\title{
Seismicity Induced by Cave Mining, Palabora Experience
}

\author{
S.N. Glazer South Africa \\ N. Hepworth Somincor, Portugal
}

\begin{abstract}
At Palabora Mining Company the seismic system is regarded as a cave monitoring tool and consequently the seismic system moved out of control of Rock Mechanics Section and has become part of Cave Management. In consequence the monitoring requirements and priorities were clarified allowing the seismic system to be planned, implemented and tested specifically for the purpose of cave monitoring. Study of seismicity associated with cave mining at PMC shows that seismic monitoring can provide a good insight into the caving process as well as being an extremely reliable and powerful tool for monitoring the progress of the cave. In this last application, seismology, by its nature, is far superior to any other cave monitoring method. The seismic system allows information to be gathered from all around the cave and is not confined to point measurements, as other methods of cave monitoring.
\end{abstract}

\section{INTRODUCTION}

In general the seismicity associated with underground mining is regarded as unfavourable due to its negative effect on safety and production caused by the associated rockbursts. The general term for seismic activity resulting from various mining operations is induced seismicity. Recent discussions attempt to distinguish between induced and triggered seismic events (McGarr and Simpson, 1997, Gibowicz and Lasocki, 2001). The main difference between induced and triggered seismic events is the factors contributing to the seismicity. In the case of the induced seismicity, the contributing factor must account for most of the stress change, or for most of the energy required to create a seismic event. Triggered seismicity takes place when the contributing factor results in a small fraction of the stress change, or it provides only small amounts of energy. Such definitions imply that human activity is the main contributing factor in case of induced seismicity, while the triggered seismicity is due primarily to pre-existing tectonic stresses. If that is the case, then the majority of seismic events observed in mines could be considered as induced seismicity, while seismic events associated for example with filling up dams and reservoirs, are triggered events. If one accepts the above definitions, then the multi-modal seismicity associated with block caving does not fit easily to either of the above categories. The seismicity due to development and undercutting in a block cave mine would be of the usual mine induced type, while the majority of seismicity due to the cave development and expansion, could possibly be classified as triggered seismicity.

\section{CAVE SEISMICITY AND LITERATURE}

The above mentioned difficulty with classification of seismicity could be considered purely academic, but it indicates that seismicity associated with cave mining is still a poorly understood phenomenon. This lack of knowledge or explanation of seismicity associated with cave mining is evident when reviewing the available seismic literature.

The first comprehensive textbook on the subject of mine seismology "An Introduction to Mine Seismology (Gibowicz and Kijko, 1994) was published in 1994. It has a very wideranging description, not only of different types of mine induced seismicity, but also of its geographical distribution in different countries and continents. But not a single reference to the block caving.

"Seismicity Induced by Mining: Ten Years Later" (Gibowicz and Lasocki, 2001) was published with the main purpose of summarising the latest developments in the field of mine seismology. This publication, as comprehensive as it is, has no information on seismicity induced or experienced with block cave mining.

"Induced Seismicity" (Knoll, 1992) is a collection of papers divided into three groups, mining induced seismicity, fluid induced seismicity and fundamentals of induced seismicity. Again there is no mention of seismicity induced or triggered by the cave mining methods.

"Seismic Monitoring in Mines" (ed. Mendecki, 1997) is mainly concerned with developing various techniques for seismic hazard estimation and it also does not mention block cave mining or associated seismicity.

The South African mine sponsored SIMRAC (Safety in Mines Research Advisory Committee) project, in operation since 1993, concentrates on fundamental research into seismic prediction and possible prevention, amelioration of rockburst damage, assessment of seismic issues, the review of past research and the transfer of the technology into industry (Adams and van der Heever, 2001). In other words SIMRAC efforts are concentrated primarily on identification of criteria for mine design in order to reduce the occurrence of seismicity and on finding measures for amelioration of the rockburst damage resulting from the seismicity. Research into seismicity triggered by cave propagation, is not part of this research.

The recently published "Block Caving Geomechanics" (Brown, 2002) includes a chapter on geotechnical monitoring that incorporates a short subchapter on microseismic monitoring. According to the author, seismic monitoring is currently used in caving mines, mainly to assist in resolving the problem caused by rockbursts that have occurred in high stress environments. This type of application for seismic monitoring is described, for example in papers by Dunlop and Geate (1995, 1997, 2001a and 2001b). Brown suggests however, that seismic monitoring has a potential to be used to study the development and mechanics of the caving process itself. 
An interesting paper on the application of seismic monitoring to study the development and mechanics of the caving process is by Duplancic and Brady (2001). In this paper the authors back analysed data from Northparks using two methods, numerical modelling and analysis of recorded seismic data. Numerical modelling was used to describe the stress around the cave crown in order to get an indication of the nature of failure mechanisms that control the caving process. Seismic data was then used to confirm the modelling results. The results from both methods indicated that slip along the pre-existing discontinuities is the controlling failure mechanism.

For several years it has been an established fact that mine induced seismicity can usually be divided into mode one events that are directly connected with the mining operations, and mode two which are associated with movement on geological discontinuities at some distance from the mining. The mode one events are associated with the formation of cracks at stope faces or in case of block cave mining, the formation of cracks in the cave back and around the periphery of the cave.

Literature on the subject of mode one events related to mining other than cave mining is extensive. In this paper we will only mention a couple of examples to illustrate that solutions already exist to explain most of the theoretical problems connected with cave induced or triggered seismicity.

Syrek and Kijko (1988) analysed the distribution of the number of events and their seismic energy against the distance of the events from a longwall face. They found that the maximum number of events is exactly at the face, while the maximum energy release emerges at some distance ahead of the face. This observation is relevant and easily applicable to the block caving situation. The distances observed by Syrek and Kijko between the position of maximum number of events and maximum energy release, were small and in order of ten meters only. The longwall height is small in comparison with the cave height, but the stress distribution pattern must, in principle, be similar. Events emitting more energy are locating in the highly stressed zone of more competent rockmass ahead of the longwall. Similarly, the a-seismic zone around the cave shown in Figure 5 illustrates this principle. The rockmass in the a-seismic zone on the immediate periphery of the longwall face is already broken and crushed with minimal stress being transmitted, thus it cannot emit significant amounts of energy. It is behaving similar to the rockmass in the a-seismic zone on the immediate periphery of the cave back where the rockmass has loosened due to the caving process.

Knoll and Kuhnt (1990) discuss two different classifications of rockbursts, which they name as mine rockbursts, or type 1 rockbursts and tectonic, or type 2 rockbursts. These two types are characterized not only by different fracture mechanisms, but also by different seismological source parameters of the focal process. Type 1 rockbursts (equivalent to mode one seismic events) are connected to face mining. For this reason their foci are located in the direct vicinity of mining openings and mostly on the longwall perimeter and in the pillars edges or advanced faces. From the rock engineering viewpoint these seismic events are bound to zones that are highly stressed and are close to a critical state due to the stress redistribution related to mining advance.

Knoll and Kuhnt suggest that in these high stress zones different activators trigger the brittle fracture connected with energy release. The geometric extensions of the focal zones correspond to the zones of stress redistribution affected by the respective local mining activities. The stiffness distribution in the rock of the focal area is then of great importance as far as the order of released energy is concerned.
Knoll and Kuhnt then describe two possible focal processes of type 1 seismic events. The first focal process is overloading of the perimeter zones with failure only in the very central part of the high stressed area. The second focal process of type 1 seismic events is connected with the development of focal areas within rock formations in the immediate roof or floor of the mining excavations where there is increased shear stress due to different stiffness of the rockmass. Here the energy emission will occur on the shear zones within the hanging or footwall strata. The damage from type 1 seismic events will occur due to the emission of seismic energy into the openings near the focal zones. This type of seismic event concentrates in the rockmass near the openings due to the maximum stiffness differences in such zones and the inherent instability of the overstressed rockmass.

Implementation of rockburst hazard mitigating methods such as stress-relief blasts, results in the reduction of the rock stiffness including reduction of shear strength. This results in increasing small shear failures in the rock, which are the mechanism of the second type of mode one seismic events.

This second type of mode one seismic event is what we are recording in the seismically active zone above the cave. The mode one events above the cave are primarily shear and are initiated by the continuous process of decreasing the rockmass stiffness above the cave back. The cause of these mode one seismic events is inelastic behaviour of the rockmass related to various aspects such as the presence of micro and macro stress concentrations, sliding along bedding planes and between rock blocks as well as initiation and propagation of micro and macro fractures. Similar conclusions were given by Rorke and Brummer (1990).

The idea of using explosives for rockburst control (preconditioning) is to stop the mechanisms that increase the horizontal clamping forces and to promote the occurrence of shear movements along fracture planes and parting planes. Both preconditioning the rockmass with explosives and the growth of the cave stimulated by drawing rock from the cave drawpoints, work essentially the same way and have the same effect on the rockmass. In block caving, the cave back progression generates fractures in the intact rock immediately ahead of the fracture zone, which alters the rock properties and reduces load carrying ability in this fractured rock. As the cave back approaches the newly fractured rock, it will yield under the increased tangential stress causing shear movement between the blocks of rock and further propagation of fractures. The cave progress will also result in breaking asperities and other locking mechanisms in the fractured rockmass creating an environment for increased shear movement and growth of the fracture zone around the cave back.

An additional mechanism also takes place around the cave due to the stress redistribution leading to further fracturing and deformations by extending the zone of fracturing ahead of the cave back. This is by both seismic and aseismic deformation. Aseismic deformation is a process of shear fracturing taking place in already existing shear fractures with little or no seismicity (Spottiswoode, 1990).

\section{PMC SEISMIC MONITORING NETWORK}

\subsection{Geology}

The Palabora copper orebody is an elliptically shaped, vertically dipping volcanic pipe. The pipe measures $1400 \mathrm{~m}$ and $800 \mathrm{~m}$ along the long and short axes. The ore reserves are proven to a depth of $1800 \mathrm{~m}$ below the surface. Copper grades of approximately $1 \%$ are found in the central core of the ore body and decrease gradually towards the peripheries with no sharp ore-waste contact. 
Mineralization is hosted by three main rock types Transgressive and banded carbonatites form the central core of the ore body and are made up of magnetite-rich sövite with minor amounts of apatite, dolomite, chondrodite, olivite and phlogopite. Barren dolerite dykes with a steeply dipping northeast trend are present as internal planned waste and account for about $8 \%$ of the ore reserve (Calder et al., 2001).

The average uniaxial strength of the carbonatites is about $120 \mathrm{MPa}$. Dolerite is a strong, brittle rock with a uniaxial strength of up to $320 \mathrm{MPa}$. Adjacent to the major faults, dolerite is locally weathered with a marked reduction in strength to around $80 \mathrm{MPa}$.

\subsection{Mining Layout}

The underground mine exploits the ore below the open pit using mechanised block caving. The undercut level is at elevation of $-800 \mathrm{~m}$ ( $1200 \mathrm{~m}$ below the surface) and approximately $400 \mathrm{~m}$ below the open pit bottom of which the elevation is $-417 \mathrm{~m}$. The production level with its drawpoints is located $18 \mathrm{~m}$ below the undercut. The Exploration Level is located less than $100 \mathrm{~m}$ below the pit bottom. The Exploration and Ventilation Shafts are located in the open pit with the collar elevation close to $100 \mathrm{~m}$ above sea level. The bank elevations of the Production and Service Shafts are on surface at close to $400 \mathrm{~m}$ above sea level.

\subsection{Seismic Network Design Philosophy}

Use of seismic monitoring networks for cave monitoring purposes is strongly influenced by the accuracy and sensitivity of the installed system. Despite underground seismic networks being widely used in mines, it is surprising how little attention is paid to the optimum design of these networks (Gibowicz and Lasocki, 2001). Their performance is usually evaluated only some time after installation and operation. The optimal configuration of seismic networks is only in a few cases predesigned and theoretically tested.

PMC experience is that, due to problems with maintaining sufficient operating seismometers to give proper seismic cover, the potential of the seismic method in monitoring and understanding cave behaviour has not been fully achieved up to the beginning of 2004. For this reason, the importance of fully implementing the seismic system, with some redundancy to allow for the inevitable equipment downtime, is currently considered to be the cave management priority.

The other important part of the seismic monitoring system that is often missing, are the data interpretation tools. In general it is accepted that the seismic monitoring structure consists of sensors, data transmission and acquisition, signal processing and finally data presentation or visualisation means. Data visualisation is often misunderstood as data interpretation. Means for data analysis and interpretation are the most important link in properly implemented and maintained seismic system.

Nowadays complete seismic systems can be purchased essentially off the shelf. There are numerous methods for optimal station configuration planning. The seismic hardware is robust and has been proven to be able to operate in very harsh underground conditions. Today most of the mines operate sophisticated systems for transferring various data from underground to their control centres and these can be easily adapted to transfer seismic data from the sensors to the seismic central site. Data storage capacity, again, with available technology, is not a problem.

Data processing is the first important link in the data interpretation procedure. Seismic databases should be constantly tested for quality and integrity. The objectives of the seismic monitoring should then be used to determine the tasks for the interpretation tools.
At PMC the seismic system was separated from the Rock Mechanics Department and classified as a cave monitoring tool and consequently the seismic system together with its seismic engineer and technician became part of the Cave Management Section. As a consequence of this, the seismic monitoring priorities were made clear, resulting in planning, testing and implementation of interpretation software specifically for the purpose of cave monitoring and management.

\subsection{Seismic Network at Palabora}

By the end of 2003 the Palabora seismic network consisted of 21 recording stations located around the cave on several levels. Nine of these stations are located on the production and development levels. Four stations are situated in the open pit. The eight remaining ones are located in the old and abandoned Exploration Shaft and in a deep borehole. The latter were installed at the beginning of 2004, as part of the network upgrade to give better coverage close to the open pit base. After completing the network upgrades the area of maximum sensitivity and location accuracy of the network encompasses the entire production area of the mine. Figures 1 and 2 show the seismic network configuration.

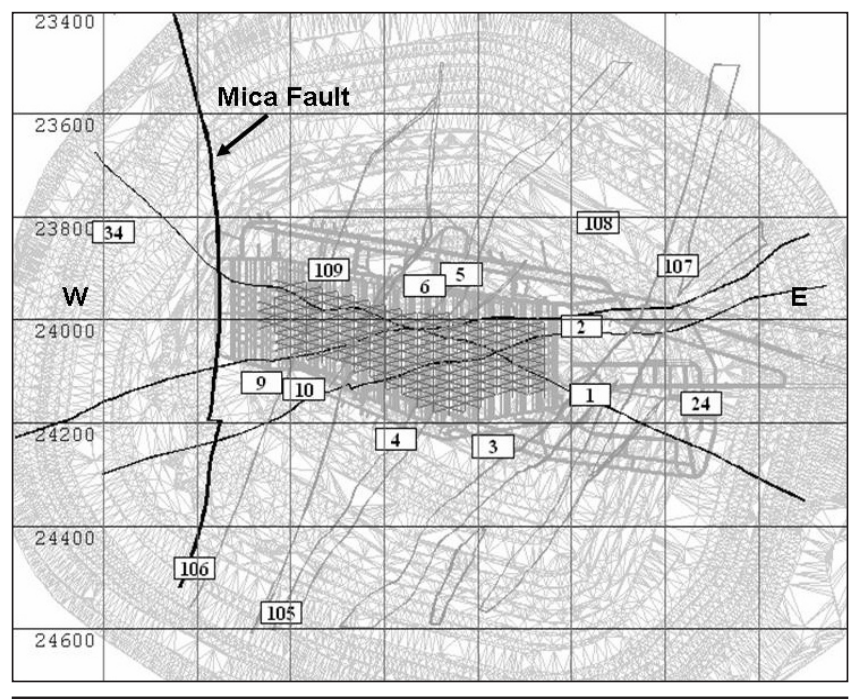

FIG. 1 Horizontal projection of PMC network

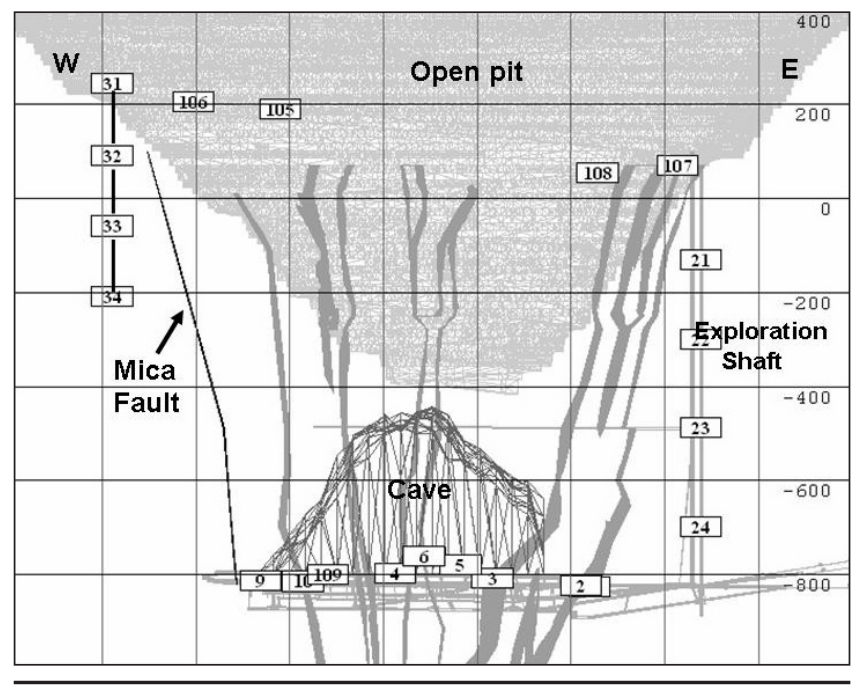

FIG. 2 Vertical projection of PMC network 


\section{DESCRIPTION OF SEISMICITY AT PMC}

\subsection{Mode One Seismic Events}

Understanding of mode one seismic events is important for understanding the processes of block cave mining. Mode one seismicity is a natural process indicating that the cave is progressing and should not only be monitored in a passive way to confirm cave progress, but also be used in an active way to manage the caving development. The space and time distributions of mode one seismic events, as well as the changes of their source parameters values with time are associated directly with what is happening in the rockmass around the cave and the mining excavations.

By nature mode one are relatively small seismic events and as such difficult to detect and record. For this reason seismic networks installed at mines using the caving method must have good sensitivity and accuracy to be effective. From PMC experience it seems that the minimum sensitivity would be all events of magnitude -2.0 and above located using at least five stations. The location accuracy should be about $10 \mathrm{~m}$.

\subsection{Mode One and Two Seismicity Mechanisms}

The ratio of S-wave to P-wave energy is an important indicator of the type of focal mechanism responsible for the generation of seismic events in the mines. There is definite evidence from natural earthquakes that the energy radiated in P-waves is a small fraction of that in S-waves, with ratio $\mathrm{E}_{\mathrm{s}} / \mathrm{E}_{\mathrm{p}}$ ranging between 10 and 30 (for example Gibowicz and Kijko, 1994). Figures 3 and 4 show this relation for mode one and two valid for mine induced PMC seismicity.

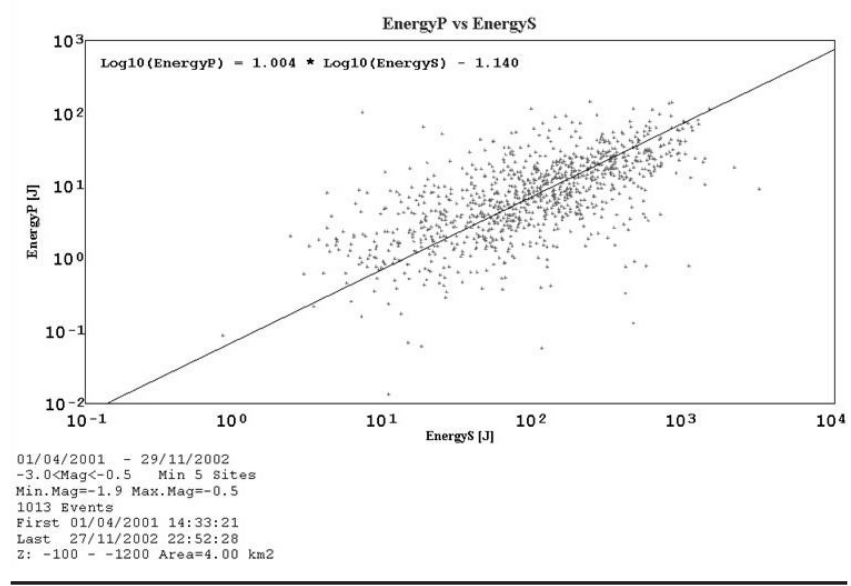

FIG. 3 Seismic events mode one, Es/Ep ratio

From the relation:

$$
\log \mathrm{E}_{\mathrm{p}}=1.004 \times \log \mathrm{E}_{\mathrm{s}}-1.140
$$

valid for the mode one PMC seismic events, the following relations are derived:

for the $\mathrm{E}_{\mathrm{s}}$ range between $10^{1} \mathrm{~J}$ and $10^{3} \mathrm{~J}$ the ratio $\mathrm{E}_{\mathrm{s}} / \mathrm{E}_{\mathrm{p}}$ is practically a constant value of 13.5 . This is generally in the magnitude range of -1 to -0.5 , which is the range in which most of the mode one events fall.

From the relation:

$$
\log E_{p}=1.144 \times \log E_{s}-1.1659
$$

valid for the mode two seismic events, the following relations are derived:

for the $\mathrm{E}_{\mathrm{s}}$ range between $10^{3} \mathrm{~J}$ and $10^{5} \mathrm{~J}$ the ratio $\mathrm{E}_{\mathrm{s}} / \mathrm{E}_{\mathrm{p}}$ ranges between 17 for the small events and 9 for the larger events. This is generally in the magnitude range of -0.5 to 1.3 , which is the range in which most of the mode two events fall. Thus the larger events have a lower shear and a higher tensile component than average.

It was found for example, that the ratio Es/Ep for small mine tremors in the Ruhr Basin, ranges from 1.5 to 30 and that for two thirds of the events this ratio was smaller than 10 (Gibowicz et al., 1990).

It is interesting to note that PMC events of mode one are more of shear type failure than the larger events of mode two. Mode one type events locate just above the a-seismic zone surrounding the cave (Figure 5). Their source is fracturing and fracture propagating which by nature is shearing.

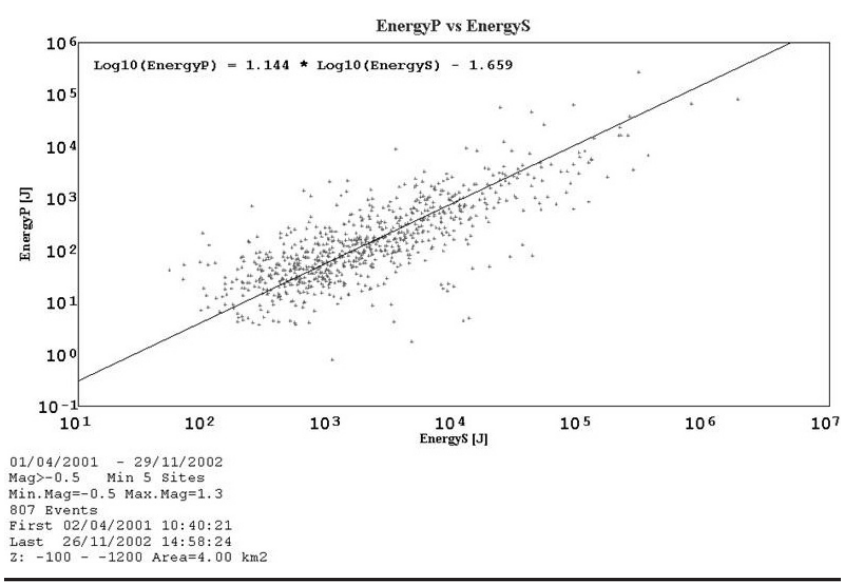

FIG. 4 Seismic events mode two Es/Ep ratio

This is in agreement with the conclusions made by Duplancic and Brady (2001). The mode two seismic events are connected with faults and dykes, and their size depends on the discontinuity geometry. The bigger sizes of mode two events locate where the faults or dykes deviate from a straight line. As a result the source has a higher tensile component. The observed general energy reduction in the S-waves implies that at PMC, as in other mines, the shear failures must also have some tensile components.

\subsection{Interpretation Applications}

Seismic monitoring provides a tool for the detection and evaluation of seismic events occurring in the rockmass due to the mining operations. While the detection itself is a reasonably simple matter, the data evaluation and their interpretation is usually a more complex problem, sometimes resulting in a number of solutions. It is a proven fact that seismicity in mines is related to mining conditions and the excavation methods. For this reason it must be possible to link seismic activity with various quantities that are characterizing mining and the rock conditions. This would allow for the number of the interpretation solutions to be limited, so that a reliance or confidence may be then attached.

\subsubsection{Mode one events to monitor progression of the cave}

At PMC mode one induced seismicity is primarily used to monitor the cave progress. The mode one seismicity is also used to monitor the behaviour of the crown pillar between the cave and the open pit, to indicate the stress distribution around the cave and to help assess the seismic hazard. This is done using the space and time distribution of seismicity as well as the various activity rates. The other parameters tested in practice are seismic energy and moment and the energy index. In this paper we will present only a couple of interpretation applications of mode one seismic events.

The tonnes extracted from the cave result in the cave back propagating upwards, towards the surface. This propagation 
is due to the rockmass fracturing above the aseismic zone. This is the source of mode one mine induced or triggered seismicity. The fracturing zone is located about 60 to $80 \mathrm{~m}$ above the cave back (Figure 5), so around the cave there is an a-seismic zone of already fractured rockmass. The thickness of this aseismic zone from April 2002 to the end of October 2002 was constant and for this reason was used as a tool to monitor the cave back position.

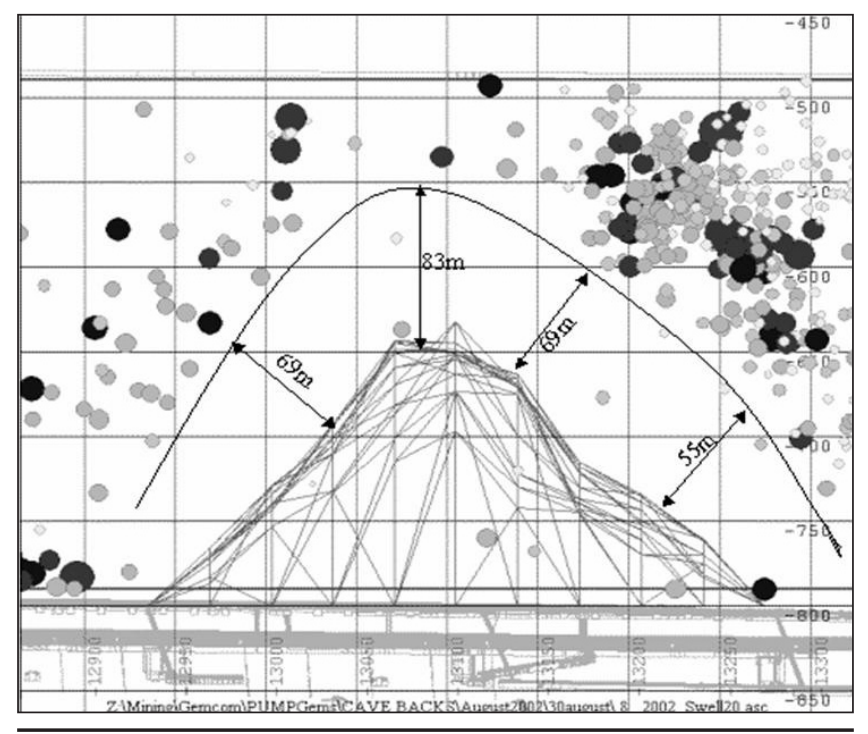

FIG. 5 A-seismic zone above the cave

This a-seismic zone thickness and its position were confirmed when drilling the eight open pit drain holes. These drain holes were terminated just above the lower boundary of the increased seismic activity zone. This is not unexpected. These drill holes were terminated due to loss of air pressure due either open geological structure or open fractures in the rock (Figure 6). The position of the cave back is for September 2002.

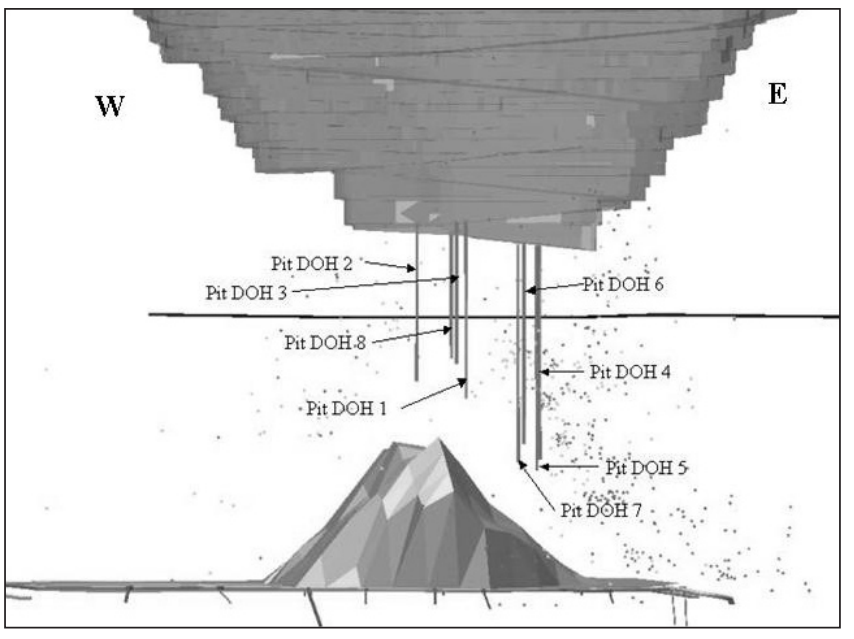

FIG. 6 Cave, pit open drain holes and seismic events

\subsubsection{Mode one events to determine maximum draw rate}

Monitoring of the extent of the a-seismic zone and of the average height increase of the recorded seismic events resulted in an estimation of the natural expansion rate of the cave. For example the increase in the average elevation of recorded events for June 2002 compared to May 2002 was $22 \mathrm{~m}$. This $22 \mathrm{~m}$ was interpreted as a change in the height of the fracture zone above the cave. The amount of material drawn from the cave in June 2002 was equivalent to an in situ height of $3.6 \mathrm{~m}$. The estimated swell factor is $20 \%$. Thus if we removed $3.6 \mathrm{~m}$ of material from the cave back and the back fell and bulked by the $20 \%$ swell factor (multiply by 6 ), then the average height of the fracture zone above the cave back would also rise $22 \mathrm{~m}$ in June if the rate of caving was exactly equal to the rate of draw. As the $22 \mathrm{~m}$ is the same, this means that the natural cave expansion rate was estimated to be close to $120 \mathrm{~mm} /$ day of equivalent in situ draw. That value was then used as the maximum permitted draw rate, as it should maintain a steady expansion void. This is important for maintaining the correct cave profile and reducing the risks connected with too large an expansion void.

\subsubsection{Mode two events to identify seismic hazard}

Mining results in changes to the stress distribution away from the mining openings or cave back as well adjacent to the openings. The stress changes tend to concentrate around geological discontinuities of different types with the geotechnical parameters of these features playing a major role in how and when accumulated energy is released. These more distal seismic events are the second mode of events. Seismic events of the second mode tend to concentrate in certain areas forming clusters of different sizes and shapes. In general, the second mode events result in increased seismic hazard due to their sizes and associated amounts of released energy.

By mid 2002, when the caving process was initiated, mode two seismic events started to concentrate on the geological discontinuities. This was recognized and the seismically active faults and dykes were identified and precautions taken where these structures intersected the workings. At that time the depth trend of the relatively large seismic events was upward, that is away from the working places. Up to the end of 2002 Palabora Mine was not experiencing seismic hazard. From the beginning of 2003 this situation changed. The pillar between the cave and the open pit became de-stressed (Glazer and Hepworth, 2004), which significantly changed the stress distribution around the mine on a regional scale. In consequence Palabora Mine became a seismically active mine, and during 2003 has experienced several rockbursts.

Comparison of seismicity recorded during 2002, with seismicity recorded during 2003 shows very significant differences. These stress changes influenced not only the small scale rockmass joints, but also especially the large scale subvertical geological features. The decrease in horizontal stress reduced confinement on the planes and increased shear movement. This is exactly what seismic data is indicating. Analysis of the source parameters of seismic events recorded in 2003 indicates a significant increase in the shearing component in addition to a major increase of released energy per moment. Another important and observed change was a nearly three-fold increase of seismic activity of magnitude 0.0 and above in 2003.

There remains a significant difference between the seismicity recorded on the west and east sides of the mine. The seismicity on the west side is much deeper and very close to the development and production levels than the seismicity on the east side. This is attributed to the more vertical cave on the west as well as the progression of the undercut footprint towards the Mica Fault. For this reason a seismic hazard warning was issued for the west side of the mine in June 2003 that resulted in additional support being installed. During the last quarter of 2003 the cave profile resulted in different stress redistribution with the west side of the mine experiencing very low stresses and the east side of the mine experienced high stress. In consequence, as from September 2003 the east side of the mine is experiencing more seismic 
events of damage potential than the west side. This stress history is indicated by the difference in the seismic source parameters of events recorded at the west and east sides of the mine.

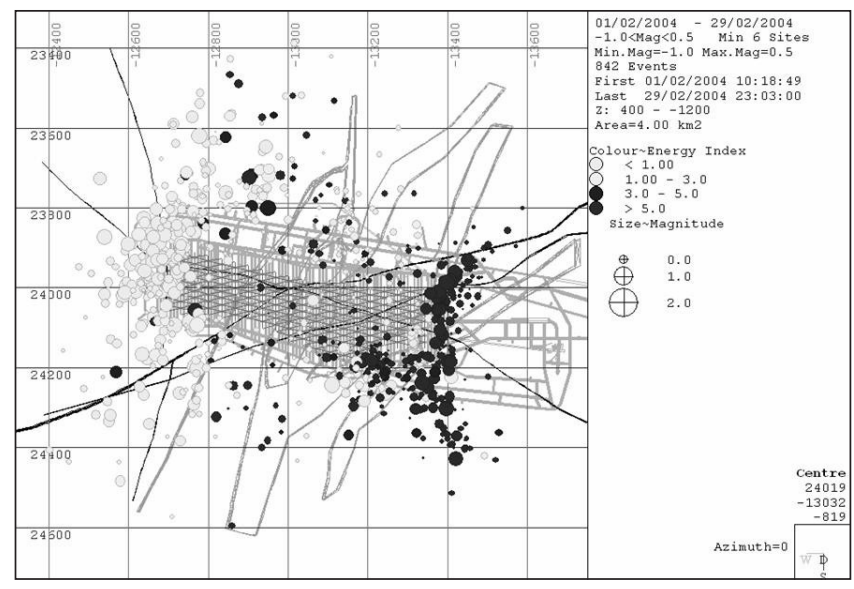

FIG. 7 Horizontal plan - stress index distribution

Figures 7 and 8 show the stress index distribution based on source parameter data recorded during February 2004. The assumption is that this index represents stress distribution in the rockmass. The higher the index, the higher is the stress in the rockmass. These two figures indicate that the stress in the rockmass on the east is much higher than the one on the west. In addition these figures indicate that the Mica Fault is no longer acting as a soft barrier to the stress transfer to the west, as there are seismic events locating west of this fault.

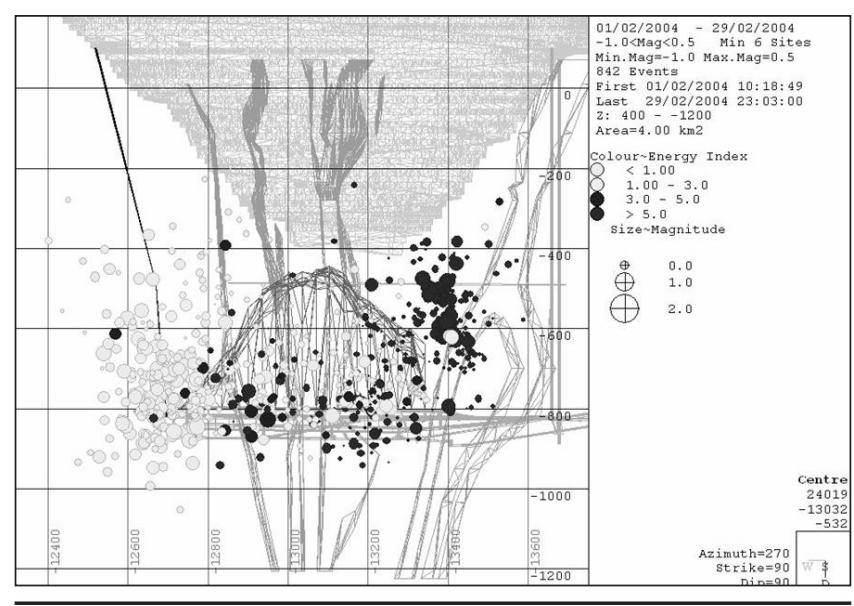

FIG. 8 Vertical plan - stress index distribution

\section{PRODUCTION AND SEISMICITY}

Distribution and rates of mine induced seismicity are directly related to the production figures as well as to its allocations. These relationships are well displayed by PMC production and seismicity. Figure 9 shows the relation between seismicity (its monthly activity rate and average depth) and the cave development phases.

Up to October 2001 there was only development taking place. Start of the production mining took place in October 2002 (Position (1) in Figure 9). Figure 9 indicates this fact by the rapid decrease of the average seismicity elevation. Seismicity migrated close to the cave to the place where production was starting to take place. The cave was then initiated by end of April 2002 (Position (2) in Figure 9) and consequently the seismicity started to migrate upwards in the same direction as the cave back. The hydraulic radius based

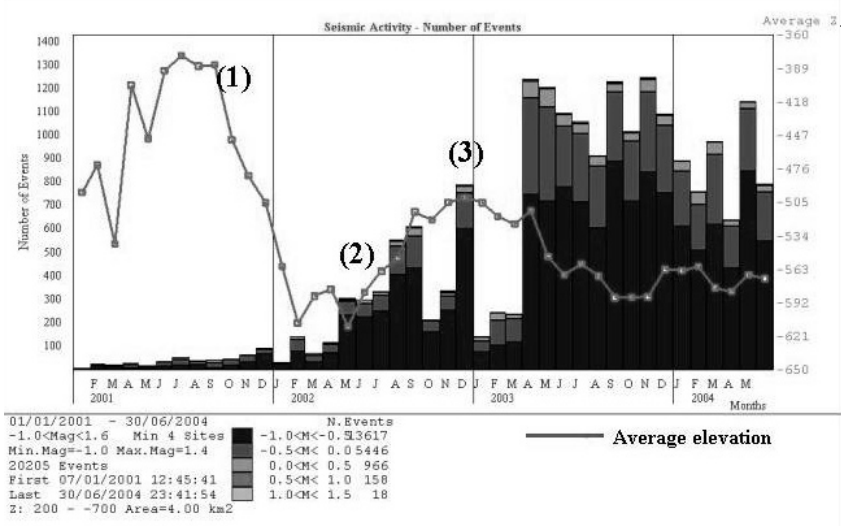

FIG. 9 Seismicity and cave development phases

on operating drawbells had reached $45 \mathrm{~m}$ in March 2002, which is similar to the hydraulic radius predicted from the Extended Mathews Stability Graph for when caving should occur in hard rocks.

At the same time the monthly seismic activity started to increase, reflecting the general increasing production from the cave. During the last quarter of 2002 (Position (3) in Figure 9) the crown pillar between the cave and the open pit has failed. As the seismicity could not take place in already de-stressed pillar it had to spread more around and away from the cave. This halt in upward migration and then the downward trend at the beginning of 2003 followed by a more level trend, is connected with the increased size and dimensions of the cave.

Figure 10 illustrates the virtual direct correlation between the amounts of released seismic energy and the amounts of tonnes pulled out of the cave. This relation seems to be changing at the beginning of 2004, when apart from seismicity directly related to the caving process, two additional influences on the seismicity start to become apparent. The first influence is related to the cave breaking through into the open pit. Seismicity is associated with movements along the wedge formed by three major faults and is restricted to the west part of the mine. Events resulting from movement on these structures are potentially of large magnitude, but due to the fact that this seismicity takes place in a low stressed and strongly fractured rockmass, these events are of relatively low energy and experience indicates that they do not result in any significant damage to the underground working places.

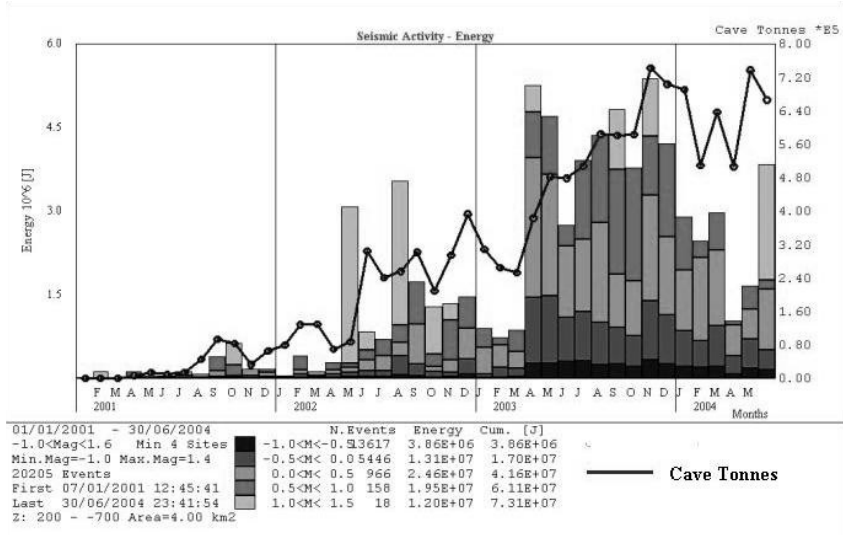

FIG. 10 Energy release and production 


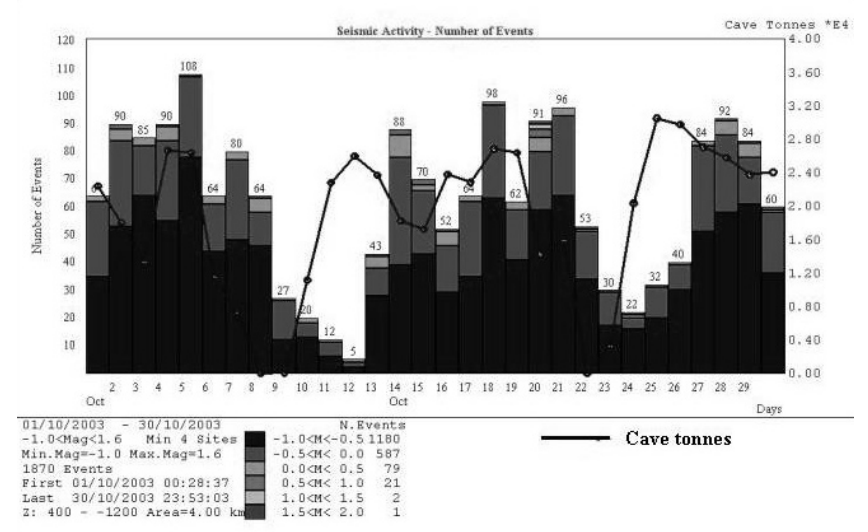

FIG. 11 Daily seismic activity rates and production

The second influence on the seismicity is directly connected with production stoppages and then resuming production after a couple of days. First such production stoppage took place in October 2003 (Figure 11).

Figure 11 shows how quickly the daily seismic activity was for the whole mine decreased when production from the cave stopped for only five days. Such fast rockmass reaction to a short production stoppage is unexpected, as normally the rockmass response to any type of mining activity is delayed. The authors have only one rational explanation. That is that there is no expansion void on top of the cave. In such a case, even for very short periods when no tonnes are pulled from the cave, the cave expansion will stop, as there is no place for the material to cave in to. Once the drawing of cave material resumes, the caving process immediately commences with material caving into the void created. From this a more general relationship might be concluded. The larger the expansion void, the longer will be the delay in the rockmass response to the production rate changes.

If the production draw rate was always kept lower than the natural cave progression rate, there should be minimal, or no, expansion void. The rapid response of the seismicity to production rate change suggests that Palabora was pulling at a rate lower than the natural cave progression rate. Thus this newer seismic data tends to support the earlier estimation of the natural cave progression rate. It should be realised that seismic activity lead to loss of all direct void measures through the open monitoring holes.

After a couple of non-production days the re-starting of production results in large energy releases (Figure 12). These large energy releasing events are considered to be more likely to occur where you have an unstable stress regime such as existing at Palabora Mine from the end of 2003 (see also Figure 7 and 8). In addition to the October 2003 production stoppage, there were two stoppages in February and April 2004. On restarting producing large seismic events resulted on the highly stressed east side of the mine.

The cave broke through into the base of the open pit in April/May 2004 and as expected, this took place with no dramatic effects. On the contrary, this break through was at first difficult to notice. By June/July 2004 the open pit started to show evidence that the break through had already taken place.

\section{PASSIVE SEISMIC TOMOGRAPHY TEST}

In July 2004, Central Mining Institute, Katowice, Poland performed a 3D passive seismic tomography analysis using data recorded at PMC (Lurka, 2002). Initial results show that the seismic tomography method has a huge potential to take

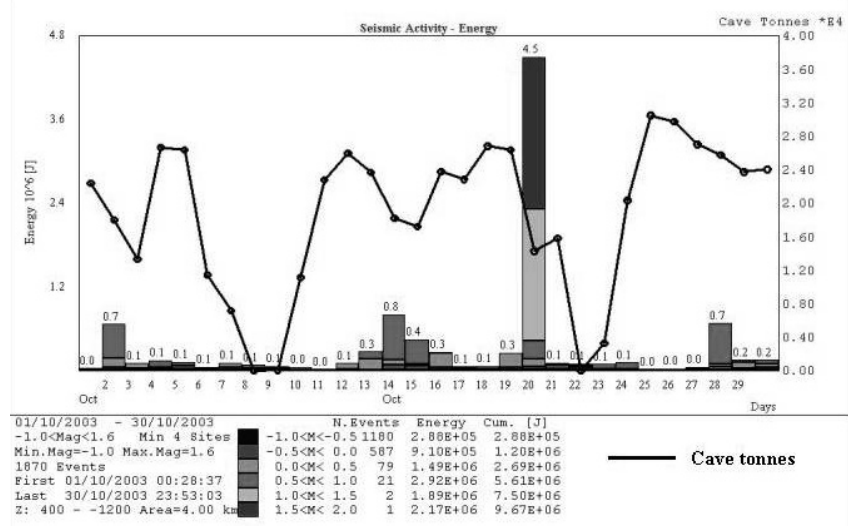

FIG. 12 Daily energy release and production

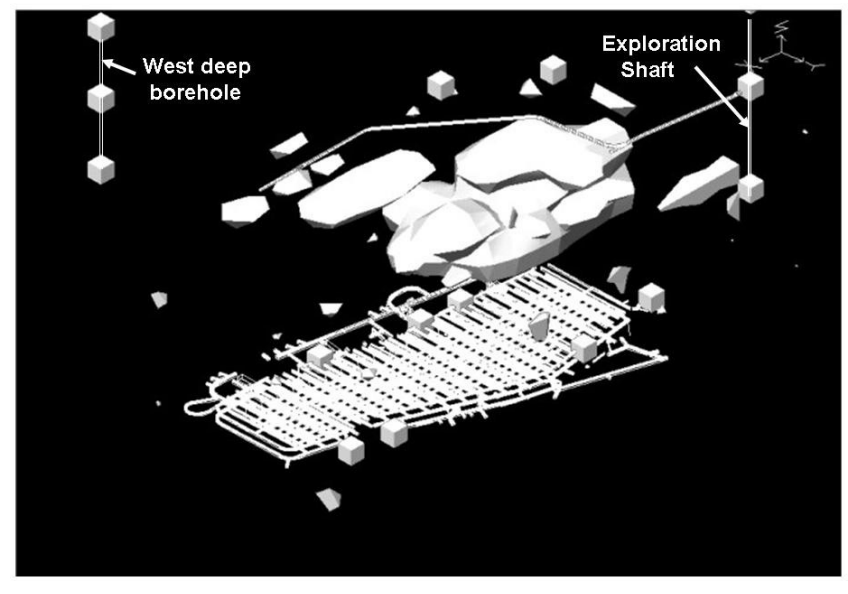

FIG. 13 May 2004 higher velocity volume

the seismic monitoring process even further. The results presented indicate that the tomography method not only provides information about the state of the rockmass around the cave, as normal seismic data does, but in addition, gives a comprehensive insight into the caved rock (Figure 13 and 14).

Inside the caved rock the higher velocity volume is probably related to poor fragmentation on the east side of the cave. The reasons for poor fragmentation are somewhat complex, but an important factor influencing the fragmentation is the geology. There is a good correlation between the boundaries of the higher velocities and the boundary of the transgressive carbonatite, where poor fragmentation was anticipated due to widely spaced joints and competent rock. Correlation between the tomography velocities and the geology model still needs to be investigated in more detail.

Figure 15 shows a horizontal surface centred on elevation of $-550 \mathrm{~m}$ ( $250 \mathrm{~m}$ above the undercut level) indicating the velocity gradients. In common with the other results, this horizontal section also indicates that the velocities at the west side of the mine are lower than those on the east. The interesting features in Figure 15 are the two distinctive high velocity gradient ridges, both in a north-south direction with the central ridge smaller than the east ridge. The velocity gradient running through the centre of the cave correlates with observed convergence at the production level that led to difficult conditions in number 11 crosscut. The second higher velocity gradient on the East side of the mine is where the seismic network recorded seismic events with high energy index values. 


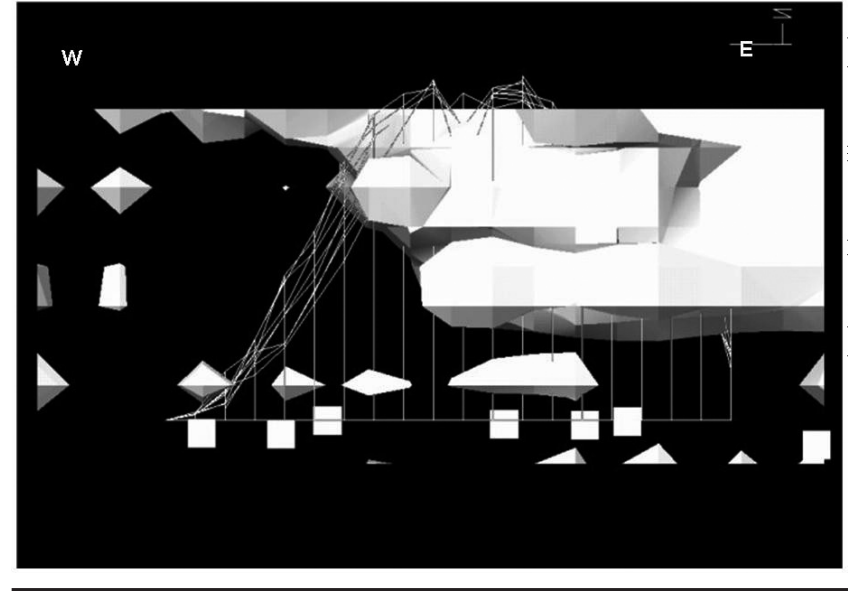

FIG. 14 West-East section through the cave

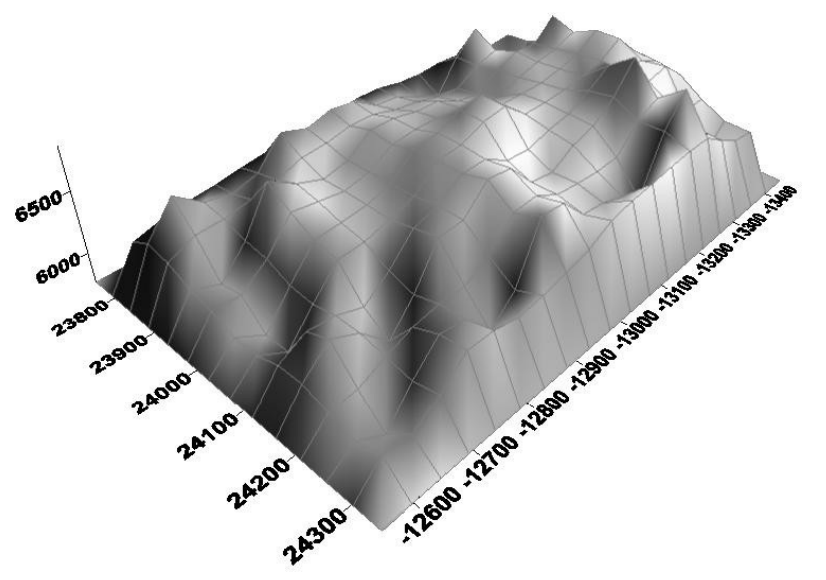

FIG. 15 Layer centred on elevation of $-550 \mathrm{~m}$

Figure 16 shows a horizontal section at an elevation of -650 $\mathrm{m}$. This section is based on data from a $100 \mathrm{~m}$ thick volume where the projection surface is located at $-650 \mathrm{~m}$. This section shows the extent of the higher velocity zone located in the centre of the cave and outside to the east of the cave. This type of section can be used to monitor time changes of the velocity images.

Quality and quantity of input data for 3D passive seismic tomography is of fundamental importance. Interpretation of tomography results is difficult and is a complex procedure. Thus there is no place for any uncertainty due to ambiguity of input data. The process of selecting proper input data sets is very important and has an enormous influence on the final results and only data recorded by well-designed seismic networks can be used with the tomography method. With poor seismic cover, the normal seismic interpretation will be capable of providing valuable information. This is not the case with seismic tomography where incorrect input data will produce worthless velocity images and their interpretations will be too distant from reality to be of any practical significance.

All required input data for seismic tomography is recorded and stored simultaneously with all other seismological data, but it forms an independent data set. Mine seismology makes use of such information as time-space distribution of recorded seismic events or of parameters such as seismic moment or energy that describe the seismic source. Seismological interpretation methods use data describing the seismic source to convert it into information relating to the rockmass surrounding this source. In this way the seismology output
April 2004, layer $-650 \mathrm{~m}$ (from $-660 \mathrm{~m}$ to $-700 \mathrm{~m}$ )

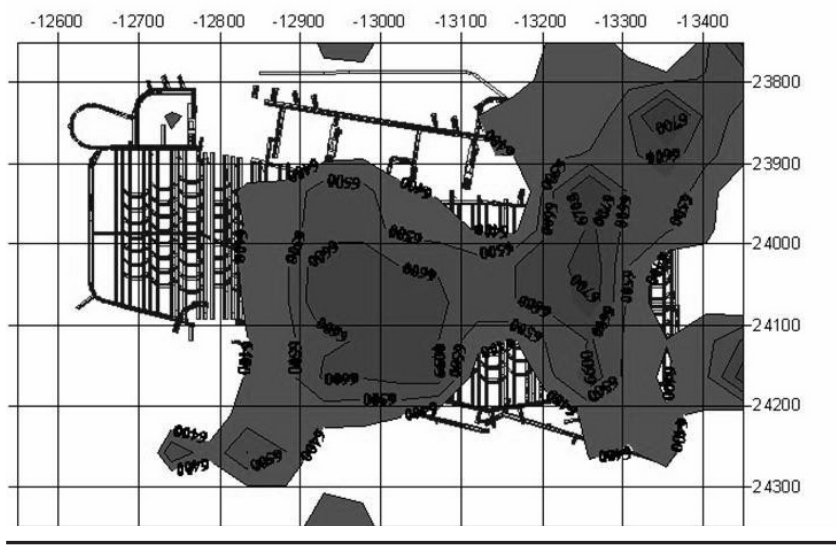

FIG. 16 Higher velocity range at level $-650 \mathrm{~m}$

is direct as far the seismic source is concerned, but indirect in describing the rockmass condition. Seismic passive tomography uses only the arrival times of the seismic waves recorded at different seismic stations and makes use of new independent input data sets to convert them directly into information about the state of the rockmass. All analysed ray traces carry direct information about the rockmass condition through which the seismic wave travels. Rockmass stress regime or/and its state of fracturing will influence the seismic wave velocity.

Massive mining, by its nature, is a process taking place in a genuine three-dimensional volume unlike tabular mining of gold or coal. Reconstruction of the velocity field itself is a complicated procedure that involves a lot of data averaging and smoothing in order to produce a result that has physical meaning. Reconstruction of a real 3D velocity field is a far more complex problem than solving the $2 \mathrm{D}$ one and as yet, is not performed anywhere in the world on regular production basis. In this way all results presented in this paper are unique. Because these Palabora data sets analysed using passive seismic tomography method show consistency and because they confirm results observed previously using mine seismology methods, the authors have a lot of confidence that they are correct.

In general the behavior of the caved material can be compared to that of the weathered material, with the difference that the weathering process goes "from top down" while in case of the caved material this process intensifies with the distance the rock moves down the cave. The tomography indicates that there is a difference in the velocities between the west and east parts of the cave. It also explains the observed problems in X/cut 11.

Thus 3D passive seismic tomography has the potential to be a very useful tool for cave mining as it allows monitoring of not only the rockmass around the cave, but also appears to allow us an insight into what is happening inside the caved rock itself.

This use of passive seismic tomography for evaluating what is happening in the caved rock was initially considered controversial, as the general view is that after the rock caves, the caved material becomes like sand that prevents the seismic waves passing through. In reality, because the caved in material has different geotechnical parameters than the rock outside the cave, it is mainly the amplitude of the wave that is attenuated. The tomography carried out at Palabora was based on the P-wave velocity.

Palabora seismic network uses two constant velocities (Vp $=6170 \mathrm{~m} / \mathrm{s}$ and $\mathrm{Vs}=3370 \mathrm{~m} / \mathrm{s}$ ) for locating seismic sources. 
Experience indicates that these calculated seismic event locations are accurate. This is apparent from the location of the seismic events mainly along faults and dykes. In cases where seismic events resulted in rockbursts the damage underground could physically confirm their locations. The majority of the seismic source locations are made including stations located around the cave. This supports the assumption that the caved in material is not a barrier for the seismic waves. In addition, if the seismic sources are correctly located, then it must imply that the caved in material has a similar seismic velocity as the rockmass outside the cave, or at least that the velocity changes are gradual.

The first results from 3D passive seismic tomography indicate that seismic tomography potentially provides an excellent tool for monitoring time related changes taking place both outside and inside the cave. Ideally this type of analysis should be repeated periodically using input data sets recorded at two or three month's intervals.

\section{APPLICATIONS OF SEISMIC MONITORING}

Understanding of mode one seismic events is important for understanding the processes of the block cave mining. Mode one seismicity is a natural process indicating that the cave is progressing and is connected with rockmass fracturing in front of the undercut and propagating cave. The space and time distributions of mode one seismicity, as well as the changes of their source parameters with time, are directly associated with what is happening in the rockmass around the cave and underground mining infrastructure. This should not only be monitored in a passive way to confirm the cave progress, but should be also used in an active way to manage the cave development. Mode one seismicity is the principal manifestation of the cave progression and thus is considered as a positive feature that allows Palabora Mine to monitor and manage the cave.

Several applications of seismic monitoring at Palabora have proven that seismic monitoring is a very valuable and useful tool not only for managing the cave mining but also for managing the transition phase from open pit to underground mining. Apart from the monitoring and management of the cave progress it was used to solve the following problems:

- Allowed for continuous underground operations during blasting operations in the open pit. In 2002 the network allowed analysis of the ground motions at the development level resulting from the blasts in the open pit. A maximum charge per delay was established that resulted in much lower PPV values than those expected to result in damage to the underground excavations.

- Evaluation of swell factor. This estimate was done by comparing the cave back profiles with different applied swell factors with the recorded space distribution of seismicity. The assumed swell factor was then confirmed by the TDR measurements.

- Recording the initiation of the caving process when the critical hydraulic radius was reached. This is important information for comparison with theoretical considerations and future design.

- Estimation of natural cave expansion rate. This allows control over the size of the expansion void, which is important for maintaining the correct cave profile and reducing the risks inherent with too large an expansion void.

- Stress distribution around the cave and underground excavations.

- Seismic hazard monitoring.

\section{ACKNOWLEDGMENTS}

The authors wish to thank the Palabora Mining Management for granting permission to publish this paper.

\section{REFERENCES}

Adams, D.J. and Van der Heever, P. (2001) An overview of seismic research co-ordinated by SIMRAC since its inception. In Rockbursts and Seismicity in Mines-RaSiM5, South African Institute of Mining and Metallurgy, pp. 205-212

Brown, E.T. (2002) Block Caving Geomechanics, Julius Kruttschnitt Mineral Research Centre, Queensland, Australia.

Calder, K., Townsend, P. and Russell, F. (2001) Palabora underground mine project. In Underground mining methods: engineering fundamentals and international case studies. (eds. Hustrulid, W.A and Bullock, R.L.). Society for Mining, Metallurgy and Exploration, Inc., Colorado, USA pp. $405-409$

Dunlop, R. and Geate, S. (1995) Seismicity at El Teniente Mine. In Proceedings of the $4^{\text {th }}$ International Symposium on Mine Planning and Equipment Selection, (eds. Singhal R. et al.) Calgary, Canada, Balkema, Rotterdam, pp. 865-869.

Dunlop, R. and Geate, S. (1997) Controlling induced seismicity at El Teniente Mine: The Sub6 case history, In Proceedings of the $4^{\text {th }}$ International Symposium on Rockburst and Seismicity in mines (eds. S.J. Gibowicz and S. Lasocki) Krakow, Poland, Balkema, Rotterdam, pp. 233-236.

Dunlop, R. and Geate, S. (2001a) An estimation of the induced seismicity related to a caving method. In Rockbursts and Seismicity in MinesRaSiM5, South African Institute of Mining and Metallurgy pp. 281-285.

Dunlop, R. and Geate, S. (2001b) Induced seismicity at El Teniente Mine: the Esmeralda sector case history. In Rockbursts and Seismicity in Mines-RaSiM5, South African Institute of Mining and Metallurgy, pp. 287-292.

Duplancic, P. and Brady, B.H.G. (2001) Understanding cave behaviour through back analysis of stress, structure and microseismicity. In Rockbursts and Seismicity in Mines-RaSiM5, South African Institute of Mining and Metallurgy, pp. 313-318

Gibowicz, S.J. and Kijko, A. (1994) An Introduction to Mining Seismology, Academic Press, New York.

Gibowicz, S.J and Lasocki, S. (2001) Seismicity Induced by Mining: Ten Years Later, Advances in Geophysics, Vol.44, Academic Press, New York.

Gibowicz, S.J., Harjes, H.P. and Schäfer, M. (1990) Source parameters of seismic events at Henrich Robert Mine, Ruhr basin, Federal Republic of Germany: Evidence for non double-couple events. Bull. Seism. Am. 80, pp. 88-109.

Glazer, S.N. and Hepworth, N. (2004) Seismic Monitoring of Block Cave Crown Pillar - Palabora Mining Company, RSA, In MassMin 2004 Proceedings, (eds. Karzulovic K. and Alfaro M.,A.), Minera Chilena, Santiago, Chile, pp.565-569.

Knoll, P. Ed. (1992) Induced Seismicity. Balkema, Rotterdam.

Knoll, P. and Kuhnt, W. (1990) Seismological and geotechnical investigations of the mechanics of rockburst. In Rockburst and Seismicity in Mines (ed. C. Fairhurst), Balkema, Rotterdam, pp. 129-138

Lurka, A. (2002) Seismic Hazard assessment in the Bielszowice coal mine using passive tomography. In Seismogenic Process Monitoring (eds. Ogasawara, T. Yanagidami and M.M. Ando) Balkema, Rotterdam.

McGarr, A. and Simson, D. (1997) Keynote lecture: A broad look at induced and triggered seismicity. In Rockbursts and seismicity in Mines (eds. S.J. Gibowicz and S. Lasocki), Balkema, Rotterdam, pp. 385-396.

Mendecki, A.J. Ed. (1997) Seismic Monitoring in Mines. Chapman and Hall, London.

Rorke, A.J. and Brummer, R.K. (1990) The use of explosives in rockburst control techniques. In Rockbursts and Seismicity in Mines (ed. C. Fairhurst), Balkema, Rotterdam, pp. 377-385.

Spottiswoode, S.M. (1990) Volume excess shear stress and cumulative seismic moment. In Rockbursts and Seismicity in Mines (ed. C. Fairhurst), Balkema, Rotterdam, pp. 39-43.

Syrek, B. and Kijko, A. (1988) Energy and frequency distribution of mining tremors and their relation to rockburst hazard in Wujek coal mine, Poland. Acta Geophys. Pol. 36, pp. 189-201. 